\title{
ON THE COMPATIBILITY \\ OF THE RECENT SOLAR PARALLAX RESULTS \\ FROM RADAR ECHOES OF VENUS \\ WITH THE MOTION OF EROS
}

\author{
By Eugene RABE, \\ University of Cincinnati Observatory.
}

RÉsumé. - L'auteur pose le problème de savoir si l'adoption d'une valeur de la parallaxe solaire telle qu'elle a été déterminée par radar, permet une représentation convenable des observations d'Éros. La solution qu'il obtient donne des résidus importants et une valeur peu vraissemblable de la masse de Mars.

Abstract. - The author investigates whether the adoption of a value of the solar parallax determined by radar measures would permit an acceptable representation of the observations of Eros. The solution he obtaines leaves important residuals and leads to a rather unlikely value for the mass of Mars.

Zusamenfassung. - Verf. untersucht die Frage, ob die Annahme eines Wertes für die Sonnenparallaxe, der durch Radarmessungen bestimmt wurde, eine annehmbare Darstellung der Erosbeobachtungen gestatten würde. Bei der erhaltenen Lösung bleiben wesentliche Residuen, in Verbindung mit einem recht unwahrscheinlichen Wert für die Marsmasse.

Резюме. - Автор ставит следущую задачу: может-ли принятие значения солнечного параллакса определенного радаром позволить удовлетворительные представления наблюдений Ероса ? Полученное решение дает значительные остатки и мало вероятное значение массеь Mapca.

Two recent determinations of the astronomical unit from radar measurements of Venus ([1] and [2]) lead to the same value $\pi_{\odot}=8^{\prime \prime} .79412 \pm 0^{\prime \prime} .00007$ for the solar parallax, if the reductions 
are made with the same value of $6378150 \pm 50 \mathrm{~m}$ for the equatorial radius of the Earth. This new value for the solar parallax is in serious disagreement, however, with the earlier result $\pi_{\odot}=8^{\prime \prime} .7984 \pm \mathrm{o}^{\prime \prime}$.ooo4, which is based on the mass $m_{\oplus+c}$ of the Earth-Moon system as derived from the observations of Eros during r $926-1945$ [3].

Since the least-squares solution of the 74 equations of condition for Eros involved a total of 16 unknowns, it seemed worth-while to investigate whether the adoption of $\pi_{\odot}=8 " .794 \mathrm{I}_{2}$ (with the associated value of $m_{\oplus+c}$ ) would still permit an acceptable representation of the Eros observations, or to what extent the average size of the residuals would increase with the changed values of the Earth perturbations. Also, while the result $\frac{\mathrm{I}}{m_{\oplus+\mathbb{c}}}=328452 \pm 43$ from the Eros solution [3] indicates a rather small probable error, a more crucial test of the true sensitivity of the final residuals against a given arbitrary variation of $m_{\oplus+\uparrow}$ and thus of $\tau_{\odot}$ may be provided by such a new solution based on some prescribed and fixed value of $m_{\oplus+\leftarrow}$.

According to de Sitter's relation as evaluated by Brouwer and Clemence [4], the above Venus echo result for $\tau_{\odot}$ will be associated with $\frac{1}{m_{\oplus+c}}=328906$. This value differs rather substantially from the result 328452 of the original Eros solution, subsequently referred to as solution I. In order to find also the effect of a smaller arbitrary variation of $\frac{I}{m_{\oplus+c}}$ on the final residuals, two new least-squares solutions have been carried out for the present study. The first of these, solution II, differs from the original solution $I$ only in so far as $\frac{I}{m_{\oplus+\complement}}$ has been kept fixed at its initial value 32839 , thus preventing the new solution from absorbing the small correction $\Delta\left(\frac{I}{m_{\oplus+\Subset}}\right)=+62$ included in solution I. This difference of the $\frac{I}{m_{\oplus+C}}$ values of solutions I and II evidently is of the order of the mean error $( \pm 64)$ of the solution I result for $\frac{\mathrm{I}}{m_{\oplus+\hookrightarrow}}$. The second new determination of all the unknowns, solution III, incorporates the fixed value $\frac{\mathrm{I}}{m_{\oplus+\Phi}}=328906$ which belongs to $\pi_{\odot}=8 " .79412$. For this solution, the initial residuals of the equations of condition were corrected first, by means of the $\bar{j}_{\oplus+\uparrow}$ coefficients listed in the original publication [3], for the effect of the change in the basic $\frac{I}{m_{\oplus+\mathbb{C}}}$ value on the computed normal positions. After the removal of the $\bar{J}_{\oplus+\propto}$ terms from the 74 equations of condition, 
solutions II and III were then obtained in the same manner as the original solution I, with $d l^{\prime \prime}=o^{\prime \prime} .00$ for the mean longitude correction of the Sun. The residuals of the two new solutions were established by substitution into the equations of condition.

TABLE 1 .

Residuals of solutions I, II and III.

\begin{tabular}{|c|c|c|c|c|c|c|c|c|}
\hline \multirow{2}{*}{\multicolumn{2}{|c|}{$\begin{array}{c}\text { Date } \\
\text { 0h E. T. }\end{array}$}} & & \multicolumn{2}{|c|}{ Solution I. } & \multicolumn{2}{|c|}{ Solution II. } & \multicolumn{2}{|c|}{ Solution III. } \\
\hline & & & $\Delta x \cos \delta$ & 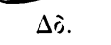 & $\Delta x \cos \delta$. & $\Delta \grave{o}$. & $\Delta x \cos \hat{o}$ & $\Delta \grave{\partial}$. \\
\hline 1926. & July & 4. & $\begin{array}{c}\prime \prime \\
-0.63\end{array}$ & -0.12 & -0.78 & -o.15 & $\begin{array}{l}\text { " } \\
+0.38\end{array}$ & $\begin{array}{l}\text { " } \\
+0.08\end{array}$ \\
\hline 1928. & Sep. & Io..... & -0.06 & -0.18 & +o.o' & -0.39 & $-1.0 \%$ & -1.16 \\
\hline \multirow[t]{9}{*}{1930.} & Oct. & Io. . & -0.03 & -0.03 & $-0.0 \mathrm{I}$ & +0.01 & $-0 . \mathrm{II}$ & -0.1 \\
\hline & & 20. & +0.27 & +0.12 & +0.33 & +0.16 & +0.15 & +0.1 \\
\hline & & $30 \ldots$. & +0.18 & +0.14 & +0.26 & +0.18 & +0.03 & +0.1 \\
\hline & Nor. & $9 \ldots$ & +0.09 & +0.26 & +0.18 ' & +0.30 & -0.05 & +0.37 \\
\hline & & I9.... & +o.14 & -0.23 & $+0.2 \%$ & -0.20 & +0.01 & -0.09 \\
\hline & & $29 \ldots \ldots$ & +0.09 & +0.10 & +0.18 & +0.12 & +0.08 & +0.28 \\
\hline & Dec. & $9 \ldots$ & +0.20 & -0.09 & +0.26 & -0.07 & +0.23 & +0.1 \\
\hline & & $19 \ldots$ & 一o.4. & +0.11 & -0.37 & +0.11 & -0.38 & +0.2 \\
\hline & & $29 \ldots$ & +0.10 & +0.16 & +0.14 & +o.rí & $+0.1 \%$ & +0.23 \\
\hline \multirow[t]{12}{*}{1931.} & Jan. & $8 \ldots$ & +0.22 & -0.15 & +0.21 & -0.2 .1 & +0.16 & -0.21 \\
\hline & & $18 \ldots$ & -0.14 & +0.23 & -0.18 & +o.14 & -0.26 & -0.03 \\
\hline & & $28 \ldots \ldots$ & -0.18 & +0.21 & $-0.2 \mathrm{I}$ & +0.08 & -0.44 & -0.19 \\
\hline & Feb. & $7 \ldots$ & +0.27 & -0.26 & +0.24 & -0.12 & +o.0í & -0.6 \\
\hline & & $17 \ldots$ & $-0.4 ?$ & -0.32 & -0.44 & -0.48 & -o.si & -0.63 \\
\hline & & $27 \ldots \ldots$ & 0.00 & -0.30 & -0.03 & 一0.任 & +0.03 & -0.54 \\
\hline & Mar. & $9 \ldots$ & +0.08 & -0.17 & +0.05 & -0.30 & +0.96 & -0.33 \\
\hline & & I $9 \ldots$ & -0.10 & +0.08 & -0.13 & -0.01 & +0.15 & -0.05 \\
\hline & & $29 \ldots$ & +0.15 & -0.04 & +0.13 & -0.10 & +0.41 & -0.16 \\
\hline & Apr. & $8 \ldots$. & $+0.0 ?$ & -0.17 & +0.01 & -0.?1 & +0.26 & -0.28 \\
\hline & & 18. & +0.09 & -0.066 & +0.09 & -0.09 & +0.25 & -0.17 \\
\hline & & 28. & +0.36 & +0.14 & +0.42 & +0.11 & +o.ji & +0.10 \\
\hline \multirow[t]{3}{*}{1933.} & Mar. & $26 \ldots$ & -1.08 & +0.61 & $-0.9^{8}$ & +0.56 & -0.99 & +0.77 \\
\hline & May & Зг.... & -0.20 & -0.12 & -0.25 & -0.10 & +0.21 & -0.10 \\
\hline & Aug. & $14 \ldots$ & +0.26 & -0.27 & +0.36 & -0.23 & +0.35 & -0.15 \\
\hline \multirow[t]{3}{*}{ 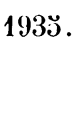 } & July & $12 \ldots$ & -0.50 & +0.04 & -0.48 & +0.10 & -0.29 & -0.16 \\
\hline & Aug. & $2 \tilde{j} \ldots$ & +0.78 & $+0.6 \mathrm{I}$ & +0.72 & +0.63 & +0.71 & +0.49 \\
\hline & Nor. & $9 \ldots$ & +0.42 & +0.05 & +0.45 & -0.0I & +0.68 & +0.13 \\
\hline $193 \bar{T}$. & Nor. & $3 \ldots$ & +0.22 . & -0.47 & +0.20 & -0.41 & +I.ji & -0.24 \\
\hline \multirow[t]{2}{*}{1938.} & Jan. & I. ..... & -0.39 & -0.38 & -0.38 & -0.40 & $+0.6 \mathrm{I}$ & -0.40 \\
\hline & Feb. & $23 \ldots \ldots$ & +0.52 & +0.66 & +0.43 & +0.56 & -1.35 & +1.34 \\
\hline 1940. & July & $30 \ldots$ & $-0.2 \mathrm{I}$ & -0.47 & +0.07 & $-0.4 \mathrm{I}$ & $-1.2 j$ & -o.1' \\
\hline 1942. & Aug. & I $3 \ldots \ldots$ & -0.03 & +0.14 & +0.01 & +0.26 & $-0.9^{j}$ & $-0.6 \mathrm{r}$ \\
\hline \multirow[t]{2}{*}{1944.} & Sep. & I5.... & +0.16 & +0.33 & +0.17 & +0.38 & +1.07 & +0.42 \\
\hline & Nov. & $30 \ldots$ & $+0.1 j$ & +0.18 & +0.19 & +0.09 & +0.29 & $+0 . j_{I}$ \\
\hline 19 学. & Feb. & $2 \ldots$ & -0.62 & +0.19 & -0.69 & +0.07 & -1.42 & -0.24 \\
\hline
\end{tabular}


All the residuals, including those of the original solution $I$, have been listed in table I. The $J x \cos o$ residual of 1930 Dec. 9.0 in solution I has been corrected to read $+0^{\prime \prime} .20$, instead of the - 0 ".20 (or rather -os.or3) in the original publication [3]. It can be seen that it is difficult to decide by mere inspection whether the residuals of solutica I or those of solution II are preferable. However, a comparison of the corresponding square sums [د] of the two sets of residuals, as listed in table II, confirms the preferableness of solution I. It is seen that $[\Delta \Delta]$ increases from 7.55 to 7.82 in consequence of the arbitrary deviation from the best value of $\frac{1}{m_{\oplus+c}}$ by less than $\frac{2}{10000}$ of its own amount. This finding supports the real significance of the formal probable error of \pm 43 of the $\frac{1}{m_{\oplus+\mathbb{c}}}$ value from solution I. The residuals of solution III clearly demonstrate the incompatibility of the observed motion of Eros with the $m_{\oplus+\overleftarrow{c}}$ value and solar parallax derived from the Venus radar measurements. For eight of the sixteen normal positions outside of the 1930-r93 i opposition, solution III leaves residuals $\Delta s$ in excess of $\pm \mathrm{I}^{\prime \prime}$. oo, where $\Delta s$ is defined by $(\Delta x \cos \hat{o})^{2}+(\Delta \hat{0})^{2}=(\Delta s)^{2}$. In solution $\mathrm{I}$, only one such $\lrcorner s$ residual exceeds $\mathrm{I}^{\prime \prime}$.oo. Furthermore, the residuals of solution III for the 2 I rather accurate and homogeneous normals of $1930-193$ r are just as unsatisfactory, because of their systematic behavior.

Table II contains the square sums $[\Delta \Delta]$ mentioned above, as well as the consequent probable errors $\mu$ of the average normal position, for all three solutions. The relevant value of $\frac{1}{m_{\oplus+\Phi}}$ is also given for each solution. The $[\Delta \Delta]$ value of solution III dwarfs those of solutions I and II, and clearly exhibits the very poor representation of the observations on the basis of an orbit of Eros which is computed with the $m_{\oplus+c}$ value provided by the $\tau_{\odot}$ result from the Venus radar measurements.

TABLE II.

Square sums $[\Delta \Delta]$ and probable errors $\mu$.

\begin{tabular}{|c|c|c|c|}
\hline \multirow[b]{2}{*}{ Solution. } & \multirow[b]{2}{*}[\Delta\Delta]{} & \multirow[b]{2}{*}{$\mu$} & 1 \\
\hline & & & $\overline{m_{\oplus+\mathbb{c}}}$ \\
\hline I... & 7.55 & \pm 0.24 & 328452 \\
\hline II... & 7.82 & \pm 0.24 & 328390 \\
\hline $111 \ldots \ldots \ldots \ldots$ & 22.29 & \pm 0.41 & 328906 \\
\hline
\end{tabular}

Considering the fact that, on the other hand, the very satisfactory representation by solution $I$ is possible, if only $m_{\oplus+c}$ is left free to assume its appropriate value, the conclusion seems inescapable that the values of $\tau_{\odot}$ and $m_{\oplus+\bullet}$ obtained from these Venus echoes cannot 
be reconciled with the observed orbital motion of Eros and thus with gravitational theory.

As to the various orbital and astronomical constants from the three different solutions, the individual corrections of solution II differ only little from those of solution I, except for somewhat larger variations of $d \mathrm{M}_{0}$ and $d s$. These two corrections are affected by the relatively greater indeterminateness of the perihelion of Eros; the sum $\left(d \mathrm{M}_{0}+d s\right)$ changes very little, too. Since solution I is the better one, the various corrections of solution II are of no further interest and therefore are not given here. As to solution III, the various fictitious values, which in their combination merely reduce as much as possible the harm done by a fixed and erroneous mass of the Earth-Moon system, are actually meaningless. It may suffice to state that nearly all the corrections of solution III are entirely different from those of solutions I and II, and that for instance the reciprocal of the mass of Mars assumes the rather unlikely value of $3027500 \pm 13$ ooo. Similarly, the mean daily motion $n$ of Eros comes out by o".ooogro smaller than from solution I, and this difference in $n$ is equivalent to longitude differences up to about $6^{\prime \prime}$ over the interval of approximately i 9 years covered by these solutions. The least squares method still reduces to the possible minimum the combined damage to the residuals, but the final residuals as well as the $[\Delta \Delta]$ of solution III prove beyond doubt the physical invalidity of this solution.

\section{REFERENCES.}

[1] G. H. Pettengill, H. W. Briscoe, J. V. Evans, E. Gehrels, G. M. Hyde, L. G. Kraft, R. Price and W. B. Smith, A Radar Investigation of Venus (Astron. J., vol. 67, 1962, p. 181).

[2] D. O. Muhleman, D. B. Holdridge and N. Block, The Astronomical Unit Determined by Radar Reflections from Venus (Astron. J., vol. 67, i962, p. г91).

[3] E. Rabe, Derivation of Fundamental Astronomical Constants from the Observations of Eros during 1926-1 945 (Astron. J., vol. 55, 1950, p. I I 2 ).

[4] D. Brouwer and G. M. Clemence, Orbits and Masses of Planets and Satellites, chapter 3 of volume III of The Solar System, The University of Chicago Press, $196 \mathrm{r}$. 